\title{
Enquiring About Tolerance (EAT) study - feasibility of early introduction of allergenic foods and impact on breastfeeding
}

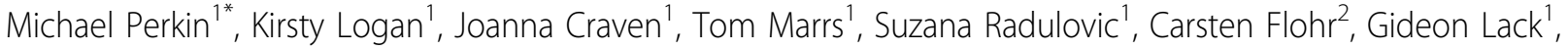 \\ EAT Study Team ${ }^{1}$
}

From Food Allergy and Anaphylaxis Meeting 2014

Dublin, Ireland. 9-11 October 2014

\section{Background}

The introduction of multiple allergenic foods in early infancy has not been attempted in a randomized controlled trial setting and the impact on breastfeeding performance is unknown.

\section{Method}

1,303 exclusively breastfeeding (EBF) infants were recruited to the EAT Study at 3 months of age and randomized to either EBF until around 6 months of age (Standard Introduction Group - SIG) or early introduction of 6 allergenic foods (cow's milk, egg, fish, wheat, sesame and peanut) alongside breastfeeding (Early Introduction Group - EIG). Data from the UK 2010 Infant Feeding Survey (IFS) was used to compare EAT Study data to UK population data.

\section{Results}

Mothers in the SIG were significantly more likely, and mothers in the EIG significantly less likely to be EBF than IFS equivalent mothers at 4, 5 and 6 months of age $(\mathrm{p}<$ 0.0005 ). Any breastfeeding rates in the two groups were very similar and significantly better than 2010 IFS equivalent mothers at 4,5 and 6 months of age $(\mathrm{p}<0.0005)$.
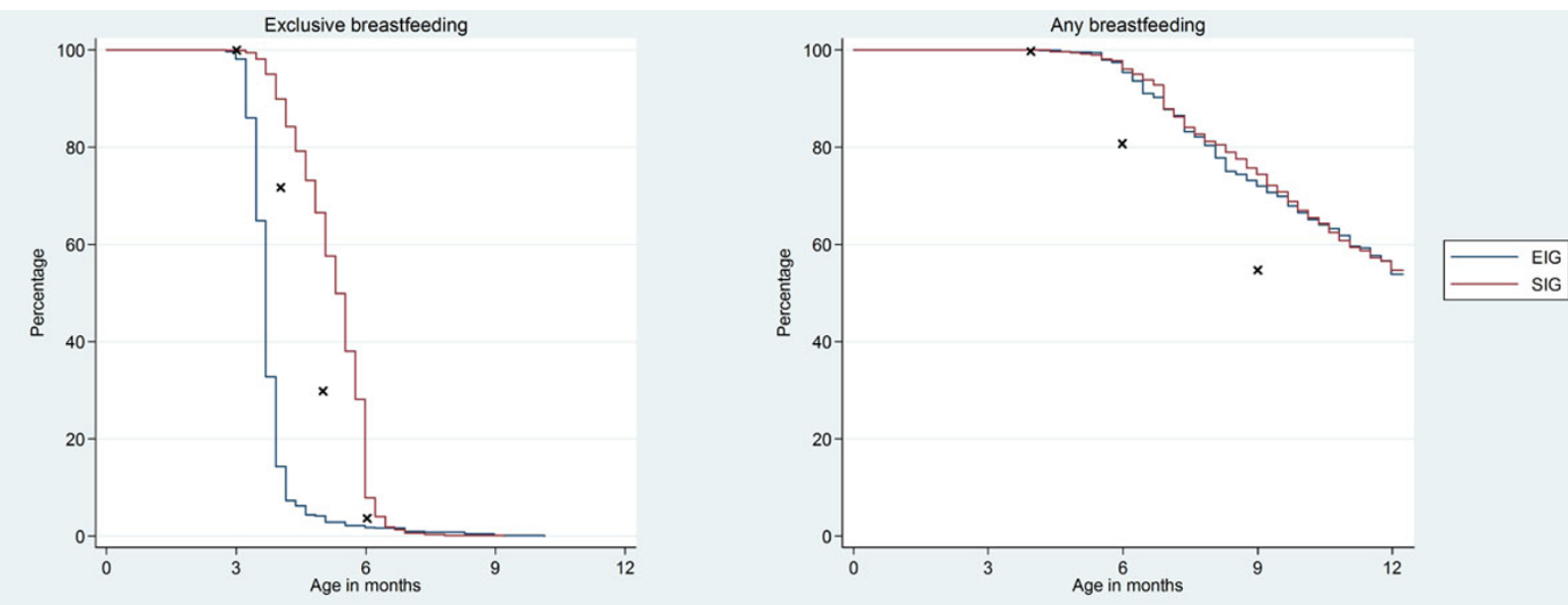

X Infant Feeding Survey 2010 Data. All comparisons between EIG or SIG and Infant Feeding Survey data at varying ages significantly different, $p<0.001$

Figure 1

${ }^{1}$ Children's Allergies Department, King's College London, London, UK

Full list of author information is available at the end of the article 
Overall per protocol compliance in the SIG was high. In the EIG, cow's milk proved to be the easiest food to introduce while sesame and egg had the slowest pace of introduction. Non-consumption rates were very low for all foods. By 5 months the median consumption frequency in the EIG was 2-3 times a week for all 6 foods with minimal consumption in the SIG. Comparisons between groups for each food at every time point were statistically significant $(\mathrm{p}<0.0005)$.

\section{Conclusion}

The EAT study is confirmation that the introduction of 6 of the principal allergenic foods in early infancy is achievable and without any deleterious effect on breastfeeding rates.

\section{Authors' details}

${ }^{1}$ Children's Allergies Department, King's College London, London, UK.

${ }^{2}$ St John's Institute of Dermatology, London, UK.

Published: 30 March 2015

\section{doi:10.1186/2045-7022-5-S3-O6}

Cite this article as: Perkin et al:: Enquiring About Tolerance (EAT) study

- feasibility of early introduction of allergenic foods and impact on

breastfeeding. Clinical and Translational Allergy 2015 5(Suppl 3):O6.
Submit your next manuscript to BioMed Central and take full advantage of:

- Convenient online submission

- Thorough peer review

- No space constraints or color figure charges

- Immediate publication on acceptance

- Inclusion in PubMed, CAS, Scopus and Google Scholar

- Research which is freely available for redistribution

Submit your manuscript at www.biomedcentral.com/submit
C Biomed Central 